\title{
Aportaciones al estudio de los balnearios romanos de Andalucía: la comarca Guadix-Baza (Prov. de Granada)
}

\author{
Francisco Diez de Velasco *
}

\section{BALNEARIOS ROMANOS: PROPUESTA DE DEFINICIÓN}

Los romanos no acuñaron un término específico para referirse a los establecimientos que utilizaban el agua termal natural o el agua de propiedades curativas. Balineum y balneum, asi como balnearius ${ }^{1}$ provenían de un préstamo antiguo del griego to balaneion; la palabra latina anterior era lauatrina ${ }^{2}$ y todas ellas presentan la indeterminación de referirse a cualquier establecimiento o sala donde se realiza la práctica del baño. Thermae ${ }^{3}$ es un término en uso en época imperial y se refería al establecimiento donde se tomaban baños calientes sin distinguir si éstos eran calentados de modo natural o artificial.

Los establecimientos que denominamos balnearios presentan características especiales que se resumen en dos criterios diferenciadores:

\footnotetext{
* Membre libre de la Casa de Velázquez. Área de Historia Antigua. Universidad de La Laguna.

1 Para estos términos consúltese TLL S.V.

${ }^{2}$ Vèase TLL S.V.

${ }^{3}$ Véase Ernout, A.; Meillet, A., Dictionnaire étymologique de la langue latine, 4 ed. París 1979, pág. 690. Recientemente se repasa magistralmente la terminologia termal en REBUFFAT, R.: "Vocabulaire thermal. Documents sur le bain romain" Les Thermes Romains, EFR 142, Roma 1991, págs. 1-32 aunque por desgracia el autor no entra a calibrar las diferencias entre termas higiénicas y establecimientos de baño termal natural.
} 
1. Frente a las termas higiénicas en las que el agua puede ser manipulada (y debe ser calentada) en los balnearios el agua no precisa para su uso del calentamiento artificial. La propia tierra actúa como calefactor y el agua surge con potencialidades multiplicadas tras su estancia subterránea ${ }^{4}$, por lo que tampoco su manipulación es deseable para no alterar su pureza. Desde el punto de vista de la técnica constructiva los balnearios no requieren el complejo sistema de hypocausta de las termas higiénicas ${ }^{5}$ (salvo casos excepcionales en que se utilizasen para calefacción como en Badenweiler ${ }^{6}$ ). Por el contrario en los balnearios que se abastecían de aguas hipertermales el verdadero problema sería dejar enfriar el agua para que pudiese utilizarse sin riesgo en el baño (tenemos una testificación epigráfica de esta práctica en Gadara -baños de Hammat Gader-) ${ }^{7}$.

2. El agua en los balnearios cura. La finalidad de los complejos balneares medicinales es la recuperación de la salud, mientras que en las termas la finalidad del baño es la higiene: la clientela de ambos será por lo tanto diferente.

En los balnearios la clientela consta mayoritariamente de enfermos, personas en una situación límite, máxime en un mundo como el grecorromano en el que la enfermedad se estima como consecuencia de un hábito de vida erróneo (desde el punto de vista de la medicina culta) ${ }^{8} 0$ como consecuencia de una imaginaria incorrección frente al sutil equili-

${ }^{4}$ Asi lo expresan por ejemplo Vitrubio VIII,3,1: «Haec autem ab natura perficiuntur his rationibus. Cum in imo per alumen aut bitumen seu sulphur ignis excitatur, ardore percandefacit terram quae est supra; sic autem feruidum emittit in superiora loca uaporem, et ita, si qui in is locis qui sunt supra fontes dulcis aquae nascuntur, offensi eo uapore efferuescunt inter uenas et ita profluunt incorrupto sapore" o Séneca Nat. Quaest. III,24,2-4: «Facere solemus dracones et miliaria et complures formas in quibus aere tenui fistulas struimus per decliue circumdatas, ut saepe eundem ignem ambiens aqua per tantum fluat spatii quantum efficiendo calori sat est; frigida itaque intrat, effluit calida. Idem sub terra Empedocles existimat fieri, quem non falli crede Baianis quibus balnearia sine igne calefiunt. Spiritus in illa feruens loco aestuarii infunditur; hic per tubos lapsus non aliter quam igne subdito parietes et uasa balnei calefacit; omnis denique frigida transitu mutatur in calidam nec trahit saporem et uaporario quia clausa praelabitur». También Oribasio $X, 3$ aclara el poder mayor de los baños minerales naturales sobre los artificiales.

${ }^{5}$ Que explica Vitrubio $(V, 11)$.

${ }^{6}$ Grenier, A., Manuel d'archéologie gallo-romaine IV,2, París 1960 págs. 460 y ss.

7 Fechada en el 455 d. C.: GREen, J.-TSAFRIR, Y., “Greek Inscriptions from Hammat Gader: a Poem by the Empress Eudocia and two Building Inscriptions", IEJ 32,1982, págs. 77-91 = SEG 32,1982, n. ${ }^{\circ} 1502$ págs. 414-416.

${ }^{8}$ Veánse los estudios de LAIN, P., La medicina hipocrática. Madrid 1982, págs. 125 y ss. o Historia universal de la medicina vol. Il: La antigüedad clásica. Barcelona 1976, passim. 
brio entre hombres, dioses y otras potencias intermedias entre ambas categorias (desde el punto de vista de lo que magistralmente Luis Gil estudió como medicina popular) ${ }^{9}$.

La cura balnear se nos presenta enfocada desde dos perspectivas que en algunos casos pueden coexistir en un mismo establecimiento:

- La cura «científica» que se realiza teniendo en cuenta las características principales de cada agua y su poder terapéutico especial (por ejemplo las distinciones entre aqua sulfurata, aluminata, bituminata, ferrata o nitrata se relacionan con diversas capacidades curativas sobre dolencias especificas) ${ }^{10}$. Ello presupone una prescripción médica (que conocemos de un modo bastante detallado por ejemplo en el caso del emperador Augusto) ${ }^{11}$ y un cierto grado de especialización dentro de la profesión ${ }^{12}$.

- La cura milagrosa, en la que una divinidad actúa por medio del agua o la propia agua se estima divina ${ }^{13}$. El poder terapéutico proviene

\footnotetext{
${ }^{9}$ GIL, L., Therapeia. Madrid 1969, passim y esp. págs. 33 y ss., 137 y ss.

${ }^{10}$ Plinio N.H. XXXI,32: «Est autem utilis sulphurata neruis, aluminata paralyticis aut simili modo solutis, bituminata aut nitrosa ... bibendo atque purgationibus» (véase el trabajo específico de Brunies, Y., L'hydrologie de Pline l'ancien. Tesis. Burdeos 1933), también Séneca Nat. Quaest. III,2,1: «Aut stant omnes aquae, aut eunt, aut colliguntur, aut uarias habent uenas. Aliae dulces sunt, aliae uarie asperae. Quippe interueniunt salsae amaraeque aut medicatae, ex quibus sulphuratas dicimus, ferratas, aluminosas; indicat uim sapor" (véase más detalles en Pierrot, A. M., L'oeuvre hydrologique de Senèque le philosophe. Tesis. Burdeos 1947) o Vitrubio VIII,3,4: «Namque sulphurosi fontes neruorum labores reficiunt percalefaciendo exurendoque caloribus e corporibus umores uitiosos. Aluminosi autem, cum dissoluta membra corporum paralysi aut aliqua ui morbi receperunt, fouendo per patentes uenas refrigerationem contraria caloris ui reficiunt, ef hoc continenter restituuntur in antiquam membrorum curationem. Bituminosi autem interioris corporis uitia potionibus purgando solent mederi» entre otros. Sobre el poder terapéutico del agua termal y mineral discutieron los médicos antiguos. Oribasio dedicó la mayor parte de su décimo libro al tema (véase Bourdy, M. F., «Du bon usage médical des bains d'après Oribase», en ChEvalLiER, R. (ed.), Les eaux thermales et les cultes des eaux en Gaule et dans les provinces voisines. Tours 1992, págs. 31-38 o PhelIPpaud, J. Y., Oribase et /hydrologie au IV siècle. Tesis. Burdeos 1935); Sorano III,12,46 la prescribe especificamente para la histeria. En general se puede consultar la introducción médica del Dr. Percepied, en Bonnaro, L., La Gaule thermale. París 1908, págs. 23 y ss. O FonTANILLE, M. T., "Les bains dans la médecine grécoromaine", en A. Pelletier (ed.) La médecine en Gaule. Villes d'eaux et sanctuaires des eaux. París 1985, págs. 15 y ss.

11 Véase por ejemplo EtIEnNe, R., «Le voyage pyrenéen d'Auguste en 26-25 antes de J. C. . Annales du Midi 64,1952 págs. 5-14.

${ }^{12}$ Mudfy, Y., «Médecins et spécialistes. Le problème de l'unité de la médecine à Rome au ler s. ap. J. C.», Gesnerus 42,1985, págs. 329 y ss.; más general JAckson, R., Doctors and Diseases in the Roman Empire. Londres 1988, esp. págs. 56 y ss..

${ }^{13}$ En última instancia al agua termal que surge del interior de la tierra se le debió de dar entre los griegos pero quizás también entre otros pueblos indoeuropeos un valor muy
} 
por lo tanto de la actuación de un principio imaginario que habita o se manifiesta en el agua; la termalidad aumenta la misteriosa potencia del rito del baño ${ }^{14}$. El caso de la invocación a las Ninfas de las Burgas de Orense ${ }^{15}$ tiene el especial intéres de mostrarnos una práctica de incubatio en un balneario: no se deja solo la curación a la acción del agua sino que se busca la revelación de la causa última del mal por parte de la divinidad, lo que se matiza y se carga de nuevos significados el fenómeno de la cura lo que nos permite atisbar la complejidad que debieron tener algunos de los establecimientos que estudiamos.

Todos estos criterios hacen necesario utilizar un concepto moderno, en la acepción moderna, como es el de balneario, para superar la indeterminación de la terminología antigua y delimitar así correctamente el campo de estudio para hacerlo más operativo.

\section{BALNEARIOS ROMANOS DE ANDALUCIAA: PROBLEMÁTICA GENERAL}

El Sur de la Península Ibérica se presenta como un territorio casi yermo en lo que se refiere al tema que nos interesa. Las testificaciones de

especial por estimarse que provenia del inframundo. Croon, J. H., The Herdsman of the Dead. Utrecht 1952, págs. 13 y ss. estudia para el mundo griego colonial estos lugares de surgimientos de aguas termales donde localiza (cada vez en posición más occidental cuanto más conocido resulta el Occidente mediterráneo para los griegos) al mítico Gerion. Resultar un agua inframundana potenciaba sus características positivas más que negativas, ya que la convertía en sagrada; una anómala emergencia de un agua subterránea y primordial, y por ello cargada de poder. Véanse estos temas tratados para el mundo griego (para el que poseemos suficientes datos) por RudhaRDT, J., Le thème de l'eau primordiale dans la mythologie grecque. Berna 1958, págs. 77 y ss. o por Ninck, M., Die Bedeutung des Wassers im Kultus und Leben der Alten. Leipzig 1921, cap. 1 entre otros.

${ }^{14}$ Véase DIEz de Velasco, F., Bainearios y divinidades de las aguas termales en la Peninsula lbérica en época romana. Madrid 1987 (ed. microfichas), págs. 31 y ss.

${ }^{15} \mathrm{CIL}$ Il, 353; más bibliografía en DIEZ DE VELASco, F., Balnearios, págs. 253-254; DiEZ DE Velasco, F., "Balnearios y dioses de las aguas termales en Galicia romana» AEA 58,1985, págs. 93-94; DíEz dE VELASCO, F., «Divinités des eaux thermales dans le Nord-Ouest de la prouincia Tarraconensis et dans le Nord de la prouincia Lusitania: une approche au phénomène du thermalisme romain dans l'Occident des provinces ibériques', en CHEVALLIER, R. (ed.), Les eaux thermales et le culte des eaux en Gaule et dans les provinces voisines. Tours 1992, pág. 135 n. 8 nota 15; Rodriguez Colmenero, A., Aquae Flaviae 1. Fontes epigráficas. Chaves 1987, págs. 100-101, n. ${ }^{\circ} 56$. 
Aportaciones al estudio de los balnearios romanos de Andalucíá...

balnearios romanos en la bibliografía especializada son pocas y en algunos casos controvertidas ${ }^{16}$. Frente al panorama que ilustran zonas más septentrionales, como Galicia, Cataluña o Extremadura, los datos que ofrece Andalucia son menos numerosos y de mucha menor entidad.

Resulta difícil no relacionar este hecho con el expolio y las destrucciones del patrimonio arqueológico que sufre Andalucia consecuencia de una especial sensibilidad de sus habitantes hacia los vestigios del pasado y una posición extremista respecto de los limites del derecho de propiedad.

Pero existen también factores que matizan estos hechos culturales y que retrotraen en parte la problemática al mundo antiguo.

Los testimonios de Aquae (ciudades de aguas) conocidos en la Península Ibérica se localizan al Norte de una línea imaginaria que uniria Oporto con Tarragona. El caso gallego es especialmente revelador puesto que los surgientes termales se convertirán en muchos casos en núcleos de concentración de población y de complejización del entramado de intercambios, superando los modos organizativos anteriores: a la hora de elegir un emplazamiento de consenso para la formación de una ciudad se eligió un lugar de prestigio como era el balneario, en el que la combinación de lo curativo y lo religioso atraía a gentes de origen diverso. En el caso andaluz este hecho no se produjo y ningún balneario llegó a alcanzar la categoria de ciudad de aguas con lo que no tenemos testimonio de ninguno de ellos ${ }^{17}$ en las fuentes literarias (las Aquae suelen aparecer

${ }^{16}$ Es lo que ocurre por ejemplo con las dos únicas termas medicinales que MorA, G. "Las termas romanas en Hispania”, AEA 54, 1981 nums. 86 y 87 pág. 57 testifica en la Bética. La del Cortijo del Ahorcado (Jaén) y a pesar de la obstinación de su descubridor (Sandars) en denominarlas establecimiento hidropático romano parecen presentar cámaras subterráneas (hipocaustos) y no existe manantial termal en las proximidades (SANDARS, H., «Apuntes sobre la apellidada "Mina de la Plata" próxima a Baeza en la provincia de Jaén”, BRAH 85, 1924, págs. 128-145). La de Torreblanca del Sol (Fuengirola, Málaga) han sido excavadas recientemente aclarándose que se trata de las termas de una villa (PUERTAS, R., "Los hallazgos arqueológicos de Torreblanca del Sol (Fuengirola)", Mainake 8-9, 1986-7, págs. 145-200; avanzan que la excavación completa se incluirá en el homenaje a Maluquer). Los Baños de Luisiana presentan una problemática especial. La excavación arqueológica de urgencia realizada en 1989, consistente en una serie de sondeos deja clara la existencia de un edificio de aprovechamiento del agua, pero cuya forma, por lo menos por lo que se desprende de la pequeña nota que ha publicado su excavador, no es la habitual en los balnearios romanos (véase SalAS, J.: "Excavación arqueológica de urgencia en los Baños de Luisiana (La Luisiana, provincia de Sevilla)» Anuario Arqueológico de Andalucía 1989, lll págs. 405-411).

$"$ De todos modos no podemos saber con toda seguridad si existieron Aquae no testificadas en fuentes escritas en esta zona, aunque de existir no debieron de ser núcleos importantes ni en la red viaria ni en cuanto a población; lo contrario de lo que ocurre en época musulmana. 
como mansiones en los itinerarios antiguos y resultan puntos de especial relevancia para la mnemotécnica geográfica antigua, por ejemplo en la Tabula Peutingeriana en que se especifican con un símbolo propio) y solo datos de interés menor en las arqueológicas (una ciudad de aguas tiene una monumentalidad arquitectónica que no posee un balneario aislado).

En el panorama arqueológico de los balnearios hispanos ni Andalucia, ni su zona oriental ofrecen conjuntos reseñables. La bibliografía especializada no testifica ni restos de la monumentalidad de los de Alanje ${ }^{18}$, ni excavados y estudiados como los de Caldes de Mombui, Caldes de Malavella o Sao Pedro do Sul.

En una lista provisional y necesariamente incompleta ${ }^{19}$ se pueden reseñar los siguientes balnearios ordenados según el grado de importancia de los restos y la seguridad de los datos:

1. Bornos (Cadiz) ${ }^{20}$. La toponimia actual es muy sugerente, Menéndez Pidal ${ }^{21}$ la relacionó con la raíz presente en el teónimo Bormanico ${ }^{22}$; lo que plasmaría el carácter termal de la localidad. En el lugar llamado Fuencaliente (o Fuente de la Sarna) se localiza

${ }^{18}$ Que se enclava en la provincia Bética pero no en la Andalucia actual, con lo que esta enumeración pierde el balneario mejor conservado de la Península lbérica y uno de los mejores que ha legado el mundo antiguo.

1 Entre otras cosas porque se han desechado obras de eruditos locales y de «cronistas" de baños por resultar en algunos casos sospechosas. Solo cuando existe una confirmación suficientemente contrastada se incluye un balneario a la lista. Fue práctica habitual en el siglo pasado la adjudicación de la fundación de la mayoria de los balnearios a los romanos. Cuanta mayor importancia tenia el balneario mas empeño existía en buscar raices romanas al mismo. Es caso de Les es especialmente ejemplar puesto que para dar mayor relieve al balneario local un falsario inventó una serie de lápidas a un espúreo dios Lex, incluidas ya como falsas por Hirschfeld en CIL XIII, $2^{*}, 3^{*}$ y $4^{*}$ (véase también LIzop, R., Les Convenae et les Consoranii. Toulouse-París 1931, pág. 269, nota 133) y que tuvieron una curiosa historia posterior. Fueron republicadas sin consultar el CIL XIII por estudiosos catalanes (que quizá no cayeron en la cuenta que el valle en el mundo romano correpondía a las Galias) y dadas por buenas (PITA, R., "Influencias ultrapirenaicas al Sur de los Pirineos centrales en la antigüedad", Actes du 94 colloque National des Sociétés Savantes. Pau 1969, pág. 24; LARA, F., Epigrafia romana de Lérida. Lérida 1973, págs. 172-174), además fueron reflejadas sin crítica en los repertorios de la época (AE 1969-1970, pág. 78 n. 276-278; HAE n. $2223-$ 2225).

${ }^{20}$ La Carisa Aurelia de Plinio $(3,15)$, más datos en Tovar, A., Iberische Landeskunde 1: Baetica. Baden Baden 1974, pág. 57.

${ }^{21}$ Menendez Pidal, R., "Sobre el substrato mediterráneo occidental», Ampurias 2, 1940 , pág. 12; Toponimia prerromana hispana. Madrid 1952, pág. 95.

${ }^{22}$ Divinidad de las aguas termales de la que aparecen dos inscripciones en Caldas de Vizella, relacionable con el dios galo de las aguas termales Borvo; véase DíEz de VeLASCO, $F$., "Divinités ...», $n .^{\circ} 15$ con bibliografía anterior y Dízz dE VELASCO, $F$., "Divindades indixenas das augas termais no extremo occidente hispano", Larouco 1, 1991, págs. 54-55. 
un enclave romano ${ }^{23}$ con el que se puede hipotéticamente relacionar la aparición de dos esculturas de Ninfas ${ }^{24}$. Pero del posible balneario romano y sus estructuras no existen datos ${ }^{25}$.

2. Alhama de Granada (Granada). Cean constata restos romanos y árabes del balneario ${ }^{26}$.

3. Alhama de Almería (Almería). Aparición de una estatua romana en las proximidades del naciente termal, así como de otros restos romanos en las cercanias ${ }^{27}$. Guichard utiliza textos árabes que hablan de la existencia de una gran piscina de agua termal en la zona, que a los árabes les parecía antigua y que por la descripción pudiera ser romana. De todos modos no parece seguro que la piscina se refiera a Alhama de Almería puesto que también pudiera referirse a Baños de Sierra Alhamilla ${ }^{28}$.

${ }^{23} \mathrm{El}$ poblamiento resulta ininterrupido desde época prerromana a la actualidad, véase CHIC, G., «Lacca», Habis 10-11, 1979-1980, págs. 260-261; se han realizado una serie de excavaciones de urgencia en la necrópolis de la ciudad por PERDIGONES, L., et alii y LAVADO, M. L., et alii publicados en Anuario Arqueológico de Andalucia 1985, III, págs. 81-98; 1986, III, págs. 67-74; 1987, III, págs. 17-25; 1988, III, págs. 113-119.

24 Garcia y Bellido, A., Esculturas romanas de España y Portugal. Madrid 1949, pág. 164, lám. 133; Rodriguez Oliva, P., «Ager Sveltitanus», BSAAV 44, 1978, pág. 385; Diez y PlatAs, F., Catálogo e iconografía de las Ninfas en la Hispania romana. Madrid 1987 (ed. microfichas, original 1983) n. ${ }^{\circ} 6$, págs. 286-289 y n. ${ }^{\circ} 7$, págs. 289-291.

${ }_{25}$ Véase DIez de Velasco, F., Balnearios ... págs. 240 y ss. La epigrafía de Bornos tampoco ayuda, solamente ha aparecido una inscripción votiva dedicada al Numen; la piedra está rota en su parte superior pero el tamaño de las letras del teónimo impide claramente que llevase ningún epíteto alusivo al tema que nos interesa (por lo que se desprende de la fotografía que incluye el editor; véase GonzÁLEZ, J., Inscripciones romanas de la provincia de Cádiz. Cádiz 1982, lám. XLIX, n. 100, págs. 68-69). El resto de la epigrafía es honorífica o funeraria; véase González, J., Op. cit. n. ${ }^{\circ}$ 97,98,99 y Rodriguez Oliva, P.- Beltrán Fortes, J., "Una inscripción dedicada a Tiberio en Carissa Aurelia», Anejos de Baetica 6, 1986, págs. 220 y ss. $=H E p$ 1, 1989, n. 215.

${ }_{26}$ Cean-Bermúdez, J., Sumario de las antigüedades romanas que hay en España. Madrid 1832, pág. 350; Díez de Velasco, Balnearios, pág. 266; Manzano, J., «El baño termal de Alhama de Granada", Al Andalus 23, 1958, pág. 408 (datos muy generales para la época preislámica). La epigrafía romana consiste en una lápida funeraria (CIL II, 5494; ILER, 2832; PASTOR, M.; MendozA, A., Inscripciones latinas de la provincia de Granada, Granada 1987, n. ${ }^{\circ} 3$, págs. 25-26) lo que no resulta relevante para nuestro trabajo (a menos que se pudiese poner en relación con una defunción al tomar las aguas lo que no resulta fácil). El balneario actual está situado en la cota 800 , presenta un caudal importante $(260 \mathrm{l} / \mathrm{s}$ ) y una temperatura de 49 grados (según CRUZ-SANJULIAN, J., et alii "Aguas termales de la provincia de Granada", Boletín Geológico y minero 83,1972 págs. 272-273; entra pues dentro del grupo de aguas hipertermales, las más explotadas en época romana.

${ }^{27}$ Véase la comunicación de Lorenzo Cara en este mismo volumen en que también cita otros hallazgos romanos de la población. En Alhama el agua surge a 45 grados (CRUZ-SANJULIÁN, J.- GARCIA-RosseLL, L., "Termalismo en España meridional», Boletín geológico y minero 86-87,1975 mapa).

${ }^{28}$ Véase la intervención de Guichard en el presente coloquio y la discusión que se suscitó respecto de la localización de la piscina. 
4. La Malahá (Granada). Aparición de sillares romanos entre las ruinas del balneario del siglo $\mathrm{XIX}^{29}$.

5. Tijola (Almería). Se testifican en torno a una fuente de aguas templadas (en un lugar denominado Cela) restos romanos (especialmente cerámica) ${ }^{30}$. Hay que añadir una lápida de la propia Tijola en la que una notable local regala unas termas a sus convecinos ${ }^{31}$. Por último existe una inscripción dudosa dedicada al Ninfo (sic!) ${ }^{32}$. Los datos sobre el hipotético balneario de Tíjola son escasos y nada plantean de las estructuras del mismo ${ }^{33}$.

6. Cortijo de Casablanca (Cádiz). G. Chic intenta situar en el Cortijo de Casablanca la ciudad antigua de Lacca de la que por fuentes medievales se sabe que poseía un manantial termal utilizado para fines curativos ${ }^{34}$. Desgraciadamente no poseemos ningún dato sobre las hipotéticas instalaciones balneares antiguas en torno al manantial termal que efectivamente existe en el Cortijo de Casablanca (proximidades de Arcos de la Frontera).

7. Baños de Gigonza (Cádiz). Chic relaciona el poblamiento romano del lugar con la explotación de la fuente termal de la localidad; pero no hay datos sobre piscinas o restos del establecimiento balnear ${ }^{35}$.

${ }^{29}$ En el Museo Arqueológico de Granada existe material fotográfico documental de las ruinas del balneario moderno de La Malahá y de los sillares romanos. En los alrededores de la localidad apareció una inscripción honorífica (PAstor, M.- MendozA, A., Op. cit n. ${ }^{\circ} 96$, págs. 184-186) que no aporta datos de interés para el tema que nos interesa. Véase DiEz DE Velasco, F., Balnearios, pág. 326. El agua surge a 26 grados con un caudal de $15 \mathrm{l} / \mathrm{s}$. y a una altura de $740 \mathrm{~m}$. (Cruz-SANJulián, J., et alii, op. cit. págs. 272-273).

${ }^{30}$ RESINA, P.- PASTOR, M., «Inscripción romana aparecida en Armunia de Almanzora (Almeria)", Zephyrus 28-29,1978 pág. 335.

${ }^{31}$ Ibidem pág. 333; LÁZARO, R., Inscripciones romanas de Almería. Almeria 1980, n. ${ }^{\circ} 48$, págs. $91-92$.

32 Esta en paradero desconocido y se conoce solamente por un manuscrito del siglo pasado (LAZARO, R., Op. cit., n. ${ }^{\circ} 49$, pág. 93). Resulta algo sospechosa, tanto por la dedicación como por la abreviatura del nomen.

${ }^{33}$ Véase DIEZ de VELASCO, F., Balnearios, págs. 283 y ss.

${ }^{34}$ CHIC, G., Op. cit. págs. 257 y ss., piensa incluso que el cementerio romano aparecido en la zona (y del que por ejemplo se destaca la lápida CIL II, 1366; GonzAlEz, J., Op. cit., n. ${ }^{\circ} 543$, págs. 286-287) se relaciona con los enfermos muertos durante el tratamiento crenoterapéutico (véase pág. 269). Sobre Lacca y su identificación insegura véase Tovar, A., Op. cit., pág. 66.

${ }^{35}$ CHIC, G., Op. cit., págs. 259-260. En el lugar se sitúa la ciudad antigua de Saguntia, más datos en Tovar, A., Op. cit., págs. 54-55. Sobre el manantial que surge a 20 grados véase su localización (CA-5) en Cruz-SanuUlián, J.- García Rossell, L., Op. cit., mapa). 
Aportaciones al estudio de los balnearios romanos de Andalucía ...

En ningún caso los datos son seguros, o resultan antiguos e incomprobables hoy en día o no se testifican construcciones balneares suficientes junto a nacimientos claramente termales o medicinales.

\section{CULTOS TERMALES Y SU PROBLEMÁTICA}

Por otra parte tampoco tenemos testificado el culto a divinidades termales en un contexto irrefutable y el caso de las Ninfas(!) de Tíjola ni está suficientemente relacionado con un manantial termal o una instalación de baños terapéuticos ni tampoco resulta suficientemente claro.

Se nos plantea un problema importante para intentar explicar el hecho del casi nulo testimonio de divinidades termales en Andalucia, en una zona por otra parte en la que han aparecido cultos romanos de todo tipo ${ }^{36}$ aunque bien es verdad que con una preeminencia de los cultos políticos. Solamente el azar en los hallazgos no puede explicar esta falta de epigrafia votiva y es posible que el argumento sea el inverso, que la inexistencia de epigrafes haya dificultado la testificación de un mayor número de instalaciones como las que estudiamos ${ }^{37}$. Probablemente la inexisten-

\footnotetext{
${ }^{36} Y$ también en cultos a divinidades salutiferas o acuáticas como son Esculapio ( 3 testimonios), Fons-Fontana ( 3 testimonios), Ninfas ( 1 testimonio) o Salus ( 3 testimonios). No existe una obra única que incluya de un modo correcto la epigrafía votiva de la Bética. Hay que referirse a Rodriguez, J., Sociedad y religión clásica en la Bética. Salamanca 1991 y a la incompleta y farragosa obra de VÁZQUEZ, A., La religión romana en Hispania. Madrid 1982. J. Delgado está realizando una tesis doctoral en la Universidad de La Laguna sobre Religión y élite en la Bética y debemos los cómputos puestos al día a su amabilidad. Hemos de agradecer a A. Stylow que nos permitiera utilizar el fichero epigráfico del CIL en el DAl de Madrid y a J. Mangas y a sus colaboradores del fichero epigráfico, su amabilidad durante las visitas al mismo.

${ }^{37}$ De algunos balnearios hispanos de época romana (cuya existencia en época antigua es segura, por ejemplo por presentar una toponimia clara) solo conocemos testificación epigráfica. Tal es el caso por ejemplo de Aquae Bilbilitanorum (Alhama de Aragón); Aquae Flaviae (Chaves); Caldelas (Amares, Portugal) o Guitiriz. En algunos lo primero que se conoció de ellos fué la epigrafía votiva que llevó posteriormente a realizar excavaciones o buscar restos, por ejemplo en Orense. De hecho la epigrafía presentó un interés mayor para los estudiosos que los restos de construcciones que se destruian o se reutilizaban desvirtuándolos, por lo que cuando hay datos epigráficos claros en balnearios la utilización romana de los mismos suele estar completamente asegurada.
} 
cia de una práctica prerromana del baño caliente ${ }^{38}$ llevó a que se nos testifique de modo tan escaso la curación termal agradecida a una divinidad (que corresponde al modo más arcaico de manifestación de la misma). Cuando los romanos importan el uso de las aguas termales en la zona andaluza la curación no se acompaña de los caracteres milagrosos que por ejemplo tiene en la zona lusitana o galaica. Así en Andalucía nos encontrariamos mayoritariamente con una práctica balnear al modo de lo que páginas atrás denominabamos cura «cientifica». Pero también es posible que el tipo de divinidad a la que se agradece una cura termal (divinidades concretas del manantial como las Ninfas o divinidades abstractas salutíferas que actúan por medio del agua como Apolo o Minerva) no correspondiese con la forma religiosa principal de la Bética, que desde luego tiende a dar culto a divinidades de tipo político ${ }^{39}$, que demostraban un estatus particular de la comunidad (ante al poder central en Roma) y del dedicante (en el seno de la élite de su comunidad). Parece que lo que podemos denominar «piedad popular» y que resulta fundamental para explicar las numerosas inscripciones de Baños de Montemayor ${ }^{40} 0$ las invocaciones a las Ninfas en la zona galaica ${ }^{41}$ no tenía la misma importancia en la Bética o no se manifestaba mayoritariamente por medio del vehículo epigráfico ${ }^{42}$.

${ }^{38}$ Es lo que colegimos de Justino 44,3 «Aqua calida lauari post Secundum Bellum Punicum a Romanis didicere». Pero Justino no habla de aguas termales naturales sino exclusivamente de agua caliente; extrapolamos el dato (que por otra parte requiere cautela dado que estas afirmaciones generales son dificilmente comprobables y presupondrian una identidad en las costumbres de los pueblos a los que se refiere Justino); si existen razones ideológicas para la no utilización de agua caliente éstas quizá abarcasen al agua termal (sobre todo si se estimaba como agua inframundana y por ello peligrosa).

${ }^{39}$ La mayoría de las dedicaciones se hacen al emperador divinizado o su genio (32 casos), a características del emperador que toman forma divina o divinidades que se distinguen mal de las anteriores al darles el epiteto Augusto/a (Virtus Augusta, Victoria Augusta -8 casos - Pax Augusta, Pietas Augusta -2 casos- Libertas Augusta, luventus Augusta, Fortuna Augusta -3 casos-, Concordia Augusta, Bonus Eventus Augustus, Lares Augusti), a entidades politicas divinizadas (Genius Coloniae - 3 casos - Genius Municipii - 8 casos-- Genius Oppidi, Genius Pagi Augusti), a divinidades que simbolizan a Roma (Lupa Lupa Romana) o a divinidades a las que se denomina con el epiteto Augusto/a detrás del cual en algún caso está la intencionalidad que destacamos (Aesculapius Augustus, Apollo Augustus, Caelestis Pia Augusta, Ceres Augusta, Diana Augusta, Hercules Augustus, Iuno Augusta, Liber Pater Augustus, Mars Augustus -6 inscripciones-, Nemesis Augusta -2 inscripciones-, Vesta Augusta, Venus Augusta -4 inscripciones--, Salus Augusta, Pantheus Augustus, Pollux Augustus). Vuelvo a agradecer a J. Delgado estas listas extraidas de su trabajo y que se refieren a inscripciones en las que el dedicante es conocido.

${ }^{40}$ Estudiadas por Roldán, J. M., «Lápidas votivas de Baños de Montemayor», Zephyrus 16, 1965, págs. 5 y ss.; también Diez de Velasco, F., "Divinités ...", nota 39, n. 22.

41 Véase Santos, J. R-Dos-Cardozo, M., «Ex votos a Ninfas em Portugal», Zephyrus 4, 1953 O DiEz dE Velasco, F., «Balnearios ...»; Diez de VelASCO, F., «Divinités ...».

${ }^{42}$ Quizá lo hiciese mediante exvotos $u$ otro tipo de manifestación más acorde con la 


\section{LA COMARCA GUADIX-BAZA Y SU POBLAMIENTO ROMANO}

Las ciudades de Guadix y Baza enmarcan una comarca de características ecológicas especiales con dos zonas de aprovechamiento humano antiguo y actual diversas. Las vegas de Guadix y de Baza presentan una fertilidad y un aprovechamiento humano intenso que permitieron en época antigua el florecimiento de dos ciudades importantes.

La mejor estudiada ${ }^{43}$ y que presenta una riqueza epigráfica notable ${ }^{44}$ es Guadix, que tuvo un estatuto colonial probablemente desde la época de Augusto (llevó el título de Colonia lulia Gemella Acci). Se convirtió en un foco de desarrollo económico al resultar un punto de paso natural entre la zona minera de Cástulo y la costa.

La Baza romana (Basti) por su parte ha legado una epigrafía escasa ${ }^{45}$ y no tuvo el privilegio colonial, por lo que los datos que poseemos sobre ella son menores.

La comarca que media entre ambas ciudades está formada por terrenos de mayor altura aptos para cultivos de secano resistentes a bajas temperaturas. Fué zona explotada en época romana para usos agrícolas como demuestra por ejemplo la existencia de dos villas romanas al Sur de Hernán Valle. Una de ellas ${ }^{46}$ presenta en superficie cimientos de lo que parece una cisterna en mortero compacto y numerosas tegulae y fragmentos cerámicos, mientras que la segunda, situada en las proximi-

práctica prerromana pero que si se realizaba en materiales perecederos no nos ha dejado rastro.

${ }^{43}$ Existe un trabajo especifico de Santero, J. M., "Colonia lulia Gemella Acci", Habis 3,1972, págs. 203-222. También Asenso, C., De Acci a Guadix. Granada 1980; Guadix, guia histórica y artística. Granada 1974; se han realizado prospecciones en la zona pero los datos publicados son escasos González Román, C., et alii, «Informe prospecciones arqueológicas en la comarca de Guadix. Campaña 1988», Anuario arqueológico de Andalucia 1988, Il, págs. 87-89.

${ }^{44}$ Las inscripciones aparecidas en Guadix son 17 de entre las que destaca una magnifica dedicación de ofrendas a Isis (CIL II, $3386=$ ILS $4422=$ SIRIS $761=$ ILER $358=$ GARCiA $_{\text {A }}$ Y BELLIDO, A., Les religions orientales dans l'Espagne romaine. Leiden 1967, págs. 109-111 $=$ PASTOR, M.- MENDOZA, A., Op. cit. n. ${ }^{\circ}$ 63, págs. 128-131 con bibliografía).

${ }^{45}$ Solo ha legado un ara a Mercurio (CIL II 3404) y una lápida funeraria (CIL II 3405) véase PASTOR, M.- MENDOZA, A., Op. cit. nums. 20-21, págs. 54-57.

${ }^{46}$ Coordenadas $37^{\circ} 20^{\prime} 55^{\prime \prime}-3^{\circ} 04^{\prime} 05^{\prime \prime}$ a una altura de $1120 \mathrm{~m}$ (hoja 993 del topográfico $1 / 50.000$, al Sur de Hernán Valle, a $1,5 \mathrm{~km}$ de Fuente Alamo, no lejos del topónimo Cuevas del Cañillo) en una localización que controla una extensa Ilanura cerealista y el paso Guadix-Gor. 
dades de una fuente (Fuenteálamo) ${ }^{47}$ presenta cerámica sigillata de buena calidad y restos de estructuras de muros en hormigón de época romana.

La vía romana principal de la zona es un ramal que unía Cartago Nova con Castulo (It. Ant. 401,5-402,5) y que pasa por Basti (It. Ant. 401,8) y Acci (It. Ant. 402,1) mal localizada en el terreno pero que debió de pasar por las inmediaciones del actual pueblo de Gor ${ }^{48}$. Una segunda vía unía Castulo con Malaca pasando por Murgi (It. Ant. 404,2-405,6) y por Acci (It. Ant. 404,6). Ambas vias toman una dirección diferente en el tramo Acci-Castulo. La primera lo hace por una zona más occidental (por Mentesa Bastiam) mientras que la segunda lo hace por un recorrido más oriental, pasando por una mansión Bactara (/t. Ant. 404,5), aún no localizada pero que pudiera situarse en la zona que nos ocupará en las páginas siguientes ${ }^{49}$. El estudio de todos estos trazados viarios sobre el terreno

${ }^{47}$ Hoja 993 del topográfico 1/50.000, topónimo principal al Sur de Hernán Valle, a 1140 metros de altitud, al pie de una zona de montes en el camino natural que los bordea para dirigirse a Almeria.

48 JIMÉNEZ COBO, M., «Ecos del enredo bastetano», El miliario extravagante 26,1990, pág.4 dice que vió restos de calzada en Gor. Blázquez y Delgado, A.- Blázqufz y Jiménez, A., “Vías romanas de Sevilla a Córdoba por Antequera .. y de Cartagena a Cástulo", MJEA 59, 19221923 pág. 17, hablan de un modo muy poco claro del itinerario del tramo. Algo más explicito dentro de lo hipotético es SILlieres, P., Les voies de communication de l'Hispanie méridionale. París 1990, pág. 285 (que repite en «La via Augusta de Carthago Nova à Accis», en Gonżález Blanco, A. (ed.), Vias romanas del Sureste. Murcia 1988, pág. 19) aunque no conoce la existencia de restos de calzada que cita Jiménez Cobo, del que desgraciadamente no hemos podido utilizar su tésis inédita «La vía romana de Cartago Nova a Castulo". Granada 1985. En una visita realizada en agosto de 1992, a la salida de Gor, en el paraje denominado «La Cuesta de Guadix» pude ver los restos de la antigua calzada romana que mantiene un empedrado somero (estos datos se incluirán en un estudio sobre las vías romanas de la zona Guadix-Baza en proceso de confección).

${ }^{49}$ El trazado de ambos ramales resulta conflictivo. Sillieres, P., Les voies.., pág. 396, opta muy hipotéticamente por llevar ambas vias juntas por el rio Fardes hasta el cerro Forruchú donde hipotéticamente sitúa la mansión Bactara, la mayoría de los autores sitúan el ramal occidental desde la salida de Guadix en una localización divergente (véanse el repaso de las hipótesis anteriores en JIMÉNEZ COBO, M., «Vías romanas de Jaén. Trayecto Mentesa Bastia-Viniolis-Agatucci», El Miliario Extravagante 23,1989, págs. 2-6). El ramal oriental presenta un trazado aún menos seguro, máxime cuando las distancias del Itinerario de Antonino entre puntos perfectamente establecidos como son Acci y Tugia es a todas luces excesiva (72 millas). Si la localización en torno a Hinojares de la mansión Fraxinum es correcta (es la que defendió SaAvedra, E., Discurso de ingreso en la Real Academia de la Historia. Madrid 1862 pág. 94 y apoya aunque sin claros argumentos arqueológicos FERNÁndeZ Chicarro, C., "Descubrimiento de una necrópolis ibérica y posible localización de la antigua Fraxinum", Zephyrus 6, 1955, págs. 293-294; "Prospección en los términos de Hinojares y La Guardia (Jaén)", Boletín del Instituto de Estudios Giennenses 2,6,1955, pág. 98); la vía seguiría el río Guadiana Menor para desembocar en Guadix. El problema radica en la localización de la mansión Bactara o Hactara puesto que las hipótesis son diversas. La más radical la defendió SaAvedra, E., Op. cit., pág. 94 y optaba por situarla al Sur de 
presenta dificultades que provienen de sus características constructivas, ya que debieron en esta zona y dada la orografía especial (existencia de ramblas que servian de vía natural de comunicación la mayoría del tiempo pero que en ciertos dias del año eran impracticables de resultas de desaguar precipitaciones tormentosas) de tener una factura muy poco sólida ${ }^{50}$.

Guadix, en el tramo de la via entre Virgi y Alba. Sitúan Bactara en una posición más alejada de Baza (aunque al Norte de Guadix, como marca el Itinerario de Antonino) los que optan por el curso del Fardes para el trazado de la vía (lo que tímidamente defendió THOUvenOT, E., Essai sur la province romaine de Bétique. París 1940, pág. 489, nota 2 y recientemente Sillieres, P., Les voies..., pág. 396 —véase nota anterior-; este parece el camino más corto y lógico desde Acci al Guadiana Menor, pero parte de la base de un fuerte error en los cómputos en millas del Itineario de Antonino). También se optó por un trazado más oriental que casi llevaba la vía en paralelo con la de Acci-Basti hasta situar Bactara en la zona de Zújar (es lo defendido en el mapa de 1936 de la Tabula Imperii Romani -y que sirvió de base para el mapa de vias romanas confeccionado en 1965 en el Instituto Geográfico y Catastral一), parece la hipótesis de BlÁZQuez y Delgado, A.- BLAZQUEZ y JiméneZ, A., Op. cit., pág. 17, que influyó en la confección de la $T I R$, la sigue sin justificar su fuente MARíN, A., "Introducción al estudio de las vias romanas en la provincia de Granada", en GonZÁLEZ BLANCo, A., (ed.), Vias romanas del Sureste. Murcia 1988, pág. 117. Ningún dato arqueológico permite defender ninguna de las dos hipótesis ya que no se han realizado prospecciones en la zona o estas no se han publicado de un modo suficiente (véase la afirmación sin apoyo de documentación de MARIN, N., et alii, «La ordenación del territorio en la Bastetania durante el alto imperio", en González Román, C., (ed.), La Bética en su problemática histórica. Granada 1991, pág. 155, situando la vía en la zona del Negratín, estos autores realizaron una prospección de la que no ofrecen más que atisbos en el artículo anterior y de la que presentaron comunicación en el Simposio L.I.M. Columela -en prensa-). Quizá razones de indole económica pudieron llevar a optar por un trazado más oriental para este ramal; SiLLIERES, P., Les voies ..., pág. 552, diserta sobre el camino argárico Almeria-Baza-Guadiana Menor que debió de ser el eje principal de la zona en época ibérica. La fundación de Acci como colonia determinó que el centro económico se desplazase hacia la zona occidental de la llanura y se privilegiase el camino del Marquesado del Zenete para dirigirse a Almeria, pero pudo quedar la parte superior del itinerario aún en uso, por razones de comodidad del trazado o porque abocase a una zona especialmente poblada que justificase el rodeo (efectivamente la falda del Jabalcón en época romana debió de estar muy poblada ya que presenta abundancia de agua, buenas tierras y altitudes inferiores a las de las zonas limitrofes; tenemos testificados restos de centuriaciones estudiadas por CANO, G., «Centuriaciones en Baza (Granada)», Estudios sobre las centuriaciones romanas en España. Madrid 1974, págs. 61-67). En cualquiera de los dos casos la vía pasaría o por las proximidades de Baños de Alicún de las Torres (si optamos por el trazado occidental por el Fardes) o por Baños de Zújar (si optamos por el trazado oriental cercano a Baza).

${ }^{50}$ Sillieres, P., Les voles..., págs. 616-617; idem, “La via Augusta...», pág. 20. 


\section{BALNEARIOS ROMANOS DE LA ZONA GUADIX-BAZA}

\section{a) Baños de Zújar ${ }^{51}$}

El balneario de Zújar se encuentra anegado en la actualidad por el pantano del Negratín y estuvo en uso hasta el año 1985 aunque en los últimos tiempos el abandono de las instalaciones provocó un deterioro progresivo del conjunto. Presenta una serie de edificios modernos para la práctica balnear que engloban el manantial, un edificio central para huéspedes y una piscina termal descubierta.

La piscina descubierta se encuentra flanqueda al Norte por una serie de edificios modernos que desvirtúan completamente las posibles estructuras antiguas. Pero en la parte Este se han conservado seis pequeñas cámaras a un nivel inferior al general del balneario que no concuerdan con la estructura moderna del edificio.

Salvo la que esta más al Norte, las cinco restantes presentan una estructura idéntica con una grada de tres escalones de $30 \mathrm{~cm}$ anegada parcialmente por el agua termal, que discurre en dirección Norte-Sur. La separación entre las distintas cámaras la forman muros cuyo encalado impide reconocer la factura. La finalidad de estas cámaras denominadas baño de pobres es permitir la inmersión en el agua termal, aunque las condiciones del mismo no resultan higiénicas puesto que no presentan ni iluminación ni ventilación.

Si retirásemos los muros de separación entre las cámaras aparecería una grada corrida de unos 17 metros de longitud. Este piso inferior no se ha mantenido en ninguno de los otros tres lados de la actual piscina descubierta aunque en el lado Norte debe encontrarse empotrado en los muros del moderno edificio. En la actualidad las cámaras de la zona Este presentan un techo abovedado muy bajo que aumenta la sensación de agobio del que penetra en ellas. Los encalados y la acción de las sales del agua termal impiden analizar a simple vista la factura de estas bóvedas, pero dado que sostienen el suelo de la planta a nivel del resto del balneario es conveniente pensar que se trata de obra moderna.

\footnotetext{
51 Situado en la falda Norte del monte Jabalcón (que culmina a $1492 \mathrm{~m}$ ) en la parte derecha del cauce del río Guadiana Menor a una altura de 618 metros. He de agradecer al ingeniero don Joaquín Delgado García su colaboración durante mi visita al balneario. El agua, sulfurosa (y cálcica-sódica-clorada) surge a 38 grados con un caudal importante - 180 I/s - (CRuz Sanjulián, J., et alii, Op. cit., págs. 272-273), solamente estas características si eran las mismas o parecidas en la antigüedad debieron de hacer al lugar muy estimado por los pobladores romanos.
} 
Aportaciones al estudio de los balnearios romanos de Andalucia ...

Esta estructura en gradas y la factura de las mismas resulta inconfundiblemente romana. Al construir el balneario moderno, y para aprovechar en parte la piscina romana se optó por mantener, aunque con una finalidad diferente una de las partes del graderio antiguo de bajada al baño.

De un modo hipotético y dada la termalidad del agua y la benignidad relativa del clima de la zona, podemos plantear que en época romana la parte central del balneario consistió en una piscina descubierta (por lo menos parcialmente) rectangular, de unos 17 metros en el lado más largo.

Debieron de existir otros edificios adosados porque en la parte Norte de las cámaras que estudiamos aparecieron una serie de piscinas más pequeñas que en algún caso se usaban como corrales de ganado. La mejor conservada, casi cuadrada y de unos tres metros de lado estaba confeccionada en hormigón compacto con un enlucido impermeabilizante.

En las proximidades de esta pequeña piscina aparecen restos de una canalización que se dirige hacia la vertiente del Monte Jabalcón. Es posible que se trate de la primitiva canalización romana porque lo que se cree que es el manantial en la actualidad y que se encuentra empotrado en el interior de los edificios modernos no abastece más que a una parte del balneario (y en especial no abastece a las cámaras que reciben agua por una canalización que entra por el Norte).

La única referencia científica del balneario de Zújar la encontramos en Lampérez y Romea ${ }^{52}$ que cita la existencia de los muros del caldarium del balneario romano. Desgraciadamente estos muros ya no eran visibles en el año 1985 por lo que no podemos saber su ubicación respecto de las estructuras romanas que subsisten. De todos modos no parece correcto hablar de caldarium en un establecimiento termal de las características del que comentamos. Es muy probable que existiese una única gran piscina de agua caliente en la que el baño no seguiría el procedimiento habitual en la práctica higiénica en termas. Al tratarse de un baño de claro contenido terapéutico no parece correcto utilizar la terminología establecida para la práctica en termas higiénicas en las que el agua es calentada artificialmente.

El poblamiento romano de la zona está poco explorado pero debió ser importante. En las proximidades del balneario (a unos $2 \mathrm{~km}$ ) se testifican

\footnotetext{
${ }^{52}$ Lampérez y Romea, V., Arquitectura civil española de los siglos lal xvill, t. 2: Arquitectura pública. Madrid 1922, pág. 466. Los datos sobre el balneario en el siglo pasado se pueden consultar en MADOZ, P., Diccionario geográfico-estadístico-histórico de España, Madrid, t. XIII pág. 677; NAvarRo, A. J., "La ciudad y el territorio de Baza", BRAH 70, 1917, 282-283 habla del balneario en el siglo xvil (se trata de la publicación en 1917 de un manuscrito de 1796). También Diez dE VELASCO, F., Balnearios, págs. 232 y ss.
} 
restos de cerámica sigillata en superficie en un emplazamiento alto ${ }^{53}$, que domina el valle donde confluyen los ríos Castril, Guardal y de Baza en el Guadiana Menor, en las zonas colindantes se testifican centuriaciones romanas que testifican el aprovechamiento de un valle fértil y bien regado ${ }^{54}$.

\section{b) Baños de Alicún de las Torres}

Las aguas termales que abastecen a moderno balneario presentan una salinidad ${ }^{55}$ que ha llevado a la formación de acueductos naturales de gran tamaño; el poblamiento calcolítico en la zona está perfectamente testificado ${ }^{56}$.

En la parte Norte del actual balneario, en el llamado Llano de los Baños, que preside la confluencia del río Fardes con el río de Gor y en la parte más cercana al establecimiento balnear moderno han aparecido restos romanos, consistentes en tegulae ${ }^{57}$, algunas completas.

Las caracteristicas del agua de Alicún de las Torres (termalidad alta y caudal abundante) no pudieron pasar desapercibidas para los pobladores romanos de la zona, máxime cuando resulta probable que en las cercanías discurriese una vía romana. Es posible que el balneario moderno se encuentre situado encima del antiguo romano, pero su uso intensivo actual impide cualquier posible comprobación.

${ }^{53}$ Se sitúa en las coordenadas $37^{\circ} 36^{\prime} 10^{\prime \prime}-2^{\circ} 47^{\prime} 22^{\prime \prime}$ y culmina a 715 metros (hoja 972 del topográfico $1 / 50.000$ a $2,5 \mathrm{~km}$ al Norte de Baños de Zújar). La cerámica romana aparece en superficie junto con cerámica árabe. Fue un emplazamiento fortificado por lo menos desde época árabe.

${ }^{54}$ Cano, G., Op. cit., pág. 65; Marín, N. et alii, Op. cit., págs. 153 y ss.; Marín, N. et alii, "Criterios actuales para el estudio de la agronomía en la antigüedad: la Hoya de Baza", Simposio L.I.M. Columela. Cádiz 1988 (en prensa).

${ }_{55}$ Las aguas surgen a 34 grados con un caudal de $80 \mathrm{l} / \mathrm{s}$ a $790 \mathrm{~m}$ y son sulfurosascálcicas (Cruz-SanıULIÁN, J. et alii, Op. cit, págs. 272-273).

56 LEISNER, G. y V., Die Megalithgräber der iberischen Halbinsel I: Der Süden. Berlín 1943, págs. 128-134; AsENJo, C., De Acci, pág. 173. CASAS, A.: «La estación prehistórica de los Baños de Alicún (Granada) Actas y Memorias de la Sociedad Española de Antropologia, Etnología y Prehistoria XXIV, 1949; CASAS, A.: «E| paleolítico de los Baños de Alicún» I CNA V CASE, Almeria 1949, págs. 45-48. En general sobre el hipotético balneario romano DiEZ DE VELASCO, F., Balnearios, pág. 268. Sobre la aparición de un sarcófago del siglo v véase AsENJo, C.: De Acci... págs. 172-173 y especialmente nota 11, pág. 173.

57 Sillieres, P., Les voies, pág. 395, nota 78, da una pequeña noticia de la aparición de restos romanos. Un pequeño paseo permite comprobar la aparición de tegulas., 
c) Baños de Graena

En Baños de Graena ${ }^{58}$, en torno al establecimiento moderno no se constatan restos romanos visibles; pero en las immediaciones, en 1984, en unas obras de desmonte para la construcción de una vivienda, aparecieron lucernas, cerámica, tegulae e incluso un pequeño capitel en mármol cuyo paradero actual es desconocido. En Graena, pueblo situado muy cerca de los Baños y del que éstos dependen hay testificada epigrafia romana ${ }^{53}$.

Aunque nada poseamos de la estructura del edificio termal romano resulta su existencia probable, (aunque dado el escaso caudal -si éste tenía parecidas características en época antigua- las construcciones no debieron ser muy importantes - tal y como ocurre en la actualidad-); como en tantos otros casos el establecimiento romano debe encontrarse debajo del actual.

\section{CONCLUSIONES}

El repaso de estos tres balnearios lleva a postular la utilidad de una labor de prospección general en balnearios andaluces. Si en una zona relativamente pequeña se testifican tres posibles (seguro en un caso) establecimientos termales romanos es lógico pensar que el número aumentaria de resultas de una labor adecuadamente planteada (con revisión de topónimos, de manantiales y de poblamiento antiguo y una prospección monográfica adecuadamente dirigida).

La excavación de un lugar que presentase condiciones óptimas sería de enorme interés ${ }^{60}$, ya que son muy pocos los balnearios hispanos en

\footnotetext{
${ }^{58}$ El agua hipertermal (44 grados) surge con un caudal escaso (5 l/s), véase Cruz-SanJULIÁN, J. et alii Op. cit., págs. 272-273.

${ }_{59}$ Una inscripción funeraria véase Pastor, M.- Mendoza, A., Op. cit., n. ${ }^{\circ} 30$ págs. 76-78. También en generai sobre el hipotético balneario DIEZ DE VELASCo, F., Balnearios, pág. 271.

${ }^{60} \mathrm{Ya}$ se trate de un balneario abandonado o sin uso moderno o que presente restos especialmente importantes que justifiquen el perjuicio social que ocasiona una actuación arqueológica en un emplazamiento de interés general como es un balneario.
} 
los que se ha realizado una actuación correcta (con presupuestos metodológicos actuales) en ese sentido ${ }^{61}$.

\section{RESUMEN}

Tras una propuesta de definición del termalismo balneario, adecuado al mundo antiguo, se listaron los balnearios romanos de Andalucía y su problemática general para posteriormente, tras una presentación de las características generales de la comarca de Guadix-Baza, repasar los balnearios de Baños de Zujar, Graena y de Alicún de las Torres, y los argumentos que permiten defender la romanidad.

\section{RÉSUMÉ}

L'article «Contribution à l'étude des établissements balnéaires romains d'Andalusie: la région Guadix-Baza" commence en proposant une définition du sujet à étude. La confection d'une liste des établissements balnéaires d'Andalusie et ses caractéristiques et l'étude sommaire de la région de Guadix-Baza aboutissent à la défanse des arguments qui permettent proposer Baños de Zujar, de Graena et d'Alicún de las Torres comme établissements d'origine romaine.

61 Los restos del balneario romano de Baños de Zújar resultan por el momento los más importantes de toda la comunidad autónoma andaluza, pero se encuentran en la actualidad anegados, por lo menos parte del año por las aguas del embalse del Negratín, lo que dificultaría su excavación; un ejemplo de la dificultad de realizar excavaciones en balnearios anegados la tenemos en Baños de Bande (el antiguo Aquis Querquernis) excavado desde hace años por A. Rodriguez Colmenero y su equipo. 